\title{
FATORES ERGONÔMICOS BÁSICOS DE POLTRONAS PARA MOTORISTAS DE ÔNIBUS RODOVIÁRIO
}

\section{BASIC ERGONOMIC FACTORS IN BUS ARMCHAIR FOR HIGHWAY DRIVERS}

\author{
Rachel Corrêa de Quadros ${ }^{1}$, Me. \\ Marcelo Gitirana Gomes Ferrreira ${ }^{2}$, PhD. \\ Noé Gomes Borges Junior ${ }^{3}$, PhD. \\ (1) Universidade Comunitária da Região de Chapecó (Unochapecó) \\ e-mail: rachelcq@unochapeco.edu.br \\ (2) Universidade do Estado de Santa Catarina (Udesc) \\ e-mail: marcelo.gitirana@gmail.com \\ (3) Universidade do Estado de Santa Catarina (Udesc) \\ e-mail: $\underline{\text { nborgesjr@gmail.com }}$
}

Fatores ergonômicos básicos, motoristas de ônibus, poltrona

\begin{abstract}
A pesquisa objetivou identificar fatores ergonômicos básicos nas poltronas de motoristas de ônibus rodoviário, ao viés do sistema técnico de leitura ergonômico proposto por Gomes Filho (2003), contribuindo para aplicação deste sistema técnico de leitura ergonômica como ferramenta projetual. As análises de tarefa dos motoristas indicaram aspectos ergonômicos na percepção do desconforto neste posto de trabalho.
\end{abstract}

Basic ergonomic factors, bus drivers, armchair

The research aimed to identify basic ergonomic factors in bus armchair for highway drivers, to the bias of the technical system of ergonomic reading proposed by Gomes Filho (2003), contributing to the application of this technical system of ergonomic reading as a design tool. The task analysis of the drivers indicated ergonomic aspects in the perception of the discomfort in this working position.

\section{Introdução}

Objetivando alcançar os melhores níveis de produtividade e confiabilidade no trabalho, profissionais e pesquisadores analisam o posto de trabalho buscando com o auxilio da ergonomia os fatores que proporcionam ao elemento humano as condições ótimas do ponto de vista fisiológico, psicológico, antropológico e sociológico. Dentre essas condições ergonômicas há requisitos 


\section{$16^{\circ}$ \\ ERGODESIGN USIHC CINAHPA}

$16^{\circ}$ Ergodesign - Congresso Internacional de Ergonomia e Usabilidade de Interfaces Humano Tecnológica: Produto, Informações Ambientes Construídos e Transporte

$16^{\circ}$ USIHC - Congresso Internacional de Ergonomia e Usabilidade de Interfaces Humano Computador

CINAHPA | 2017 - Congresso Internacional de Ambientes Hipermídia para Aprendizagem. primordiais a serem analisados como, por exemplo, o conforto de uma poltrona de posto de trabalho. Para Grandjean (1998, p.294): “a garantia de um clima confortável no ambiente é, assim, um prérequisito necessário para a manutenção do bemestar e para a capacidade de produção total.". Entende-se neste sentido que a busca pela melhoria no design de produtos vai ao encontro da necessidade da qualidade de vida dos usuários. Foi nesta reflexão que a presente pesquisa visou entender e apontar estas melhorias, a fim de oferecer subsídios à definição de requisitos para o desenvolvimento de produtos do setor transporte rodoviário, com enfoque nas poltronas de postos de trabalho de motoristas.

Nesse sentido, o problema desta pesquisa foi descrever os principais aspectos relevantes aos fatores ergonômicos básicos, pautados pelo sistema técnico de leitura ergonômica de Gomes Filho (2003) no que diz respeito á poltrona no posto de trabalho do motorista de ônibus rodoviário, para proposições uma listagem de fatores e aspectos que devem ser relevantes a fim de buscar melhorias na qualidade de vida dos trabalhadores. Neste trabalho foi possível identificar as diferenças entre a teoria e prática (mercado), evidenciando as necessidades aplicadas na eficácia, eficiência e satisfação dos motoristas na interação com seu instrumento de trabalho e a relação do design com relação às atividades diárias destes motoristas que realizam seu trabalho em longas jornadas de viagens que incluem: necessidade de deslocar o banco no sentido horizontal para colocar-se e sair do assento, número excessivo de movimentos repetitivos, revestimento do assento de material sintético ocasionando desconforto devido à transpiração; problemas posturais entre outros fatores relacionados ao posto de trabalho do condutor.

\subsection{Objetivo}

O objetivo deste projeto foi apontar os fatores ergonômicos básicos de poltronas para motoristas de ônibus rodoviário, que pudessem dinamizar o entendimento dos critérios ergonômicos que minimizem os efeitos prejudiciais no uso de poltronas no auxílio para projetar este artefato.

\subsection{Materiais e Métodos}

Para a presente pesquisa o sistema técnico de leitura ergonômica proposto por Gomes Filho (2003) foi o alicerce proposto para uma averiguação de fatores ergonômicos que são considerados essenciais em um artefato projetado para um posto de trabalho. Na pesquisa propôs-se que este sistema auxiliou de forma simplificada no entendimento de uma análise ergonômica rápida. Os procedimentos metodológicos adotados foram de natureza aplicada, descritiva e experimental, realizada por meio de um estudo de caso em uma determinada uma empresa carroceira, localizado no Rio Grande do Sul, Brasil. A listagem destes fatores ergonômicos básicos pode ser concluída através da análise de dados quali/quanti realizada em 2 etapas. A primeira consistiu em entrevistas estruturadas, onde foram entrevistados 07 (sete) designers, a fim de entender a relação dos fatores ergonômicos na concepção projetual das poltronas dos motoristas. Nesta mesma etapa foi realizada uma pesquisa de campo, no setor de desenvolvimento e produção averiguando os processos de desenvolvimento do habitáculo do motorista, com enfoque na poltrona deste posto de trabalho. A segunda etapa consistiu em uma avaliação antropométrica, aplicada em 08 (oito) motoristas, com a finalidade de verificar a média das medidas destes trabalhadores comparando ao padrão das medidas brasileiras utilizados nos projetos de habitáculos de motoristas de ônibus, assim como também nesta etapa foi aplicado questionário aos motoristas, buscando apontar os fatores ergonômicos básicos na interação com sua poltrona. As perguntas do questionário foram elaboradas conforme delineamento do sistema de leitura Ergonômica proposta por Gomes Filho (2003), que será abordado no item 2.1.

\section{Referencial Teórico}

\subsection{Sistema Técnico de Leitura Ergonômica}

Entende-se que o campo da ergonomia, devido ao seu caráter multidisciplinar, evolui continuamente

\section{Realização: ")




\section{$16^{\circ}$ \\ ERGODESIGN USIHC CINAHPA}

em virtude do avanço de diversas áreas do conhecimento, como a fisioterapia, as engenharias, a medicina do trabalho, bem como o design, que contribuem para entender melhor as lacunas existentes neste objeto de estudo. Nesta pesquisa adotou-se uma premissa teórica como base para entender a relação projeto de produto, design e ergonomia. Sabe-se que esta área de conhecimento envolve um campo bastante vasto, e preocupa-se com os mais diversos tipos de trabalho, objetivando o conforto e a segurança do profissional e consequentemente a eficiência do trabalhador. Cabe observar no que há uma correlação entre níveis de conforto e segurança do trabalhador e entre a eficácia e a produtividade resultante. A relação entre as tarefas que o trabalhador deve desempenhar e os maiores confortos para a realização das mesmas estão ligados a um aumento da produtividade. Qualquer tipo de desconforto (emocional ou físico) no trabalho gera desconcentração, inquietação, malestar, insatisfação e pode culminar em afastamentos por problemas de saúde. Para estar em sintonia com a atual valorização do ser humano, é importante conhecer as condições da ergonomia, tanto na hora de abrir, como de reformar um posto de trabalho (Iida, 2005). Neste sentido e tendo empiricamente observado a insuficiência de estudos que tratem diretamente sobre a relação entre design versus ergonomia para prática projetual, definiu-se como referência básica o autor Gomes Filho (2003). O Sistema Técnico de Leitura proposto pelo autor Gomes Filho (2003), publicado em seu livro Ergonomia do Objeto, que resulta em parte da tese de doutorado, tem como objetivo facilitar as atividades de concepção e desenvolvimento de produto, identificando a contribuição da aplicação do campo do conhecimento da ergonomia como tecnologia projetual e de um modo mais amplo dentro da autêntica cultura ergonômica, intrinsecamente ligada á metodologia do design.

O autor Gomes Filho (2003, p. 22) ressalta:

"[...] procuramos refletir sobre uma cultura de aplicação ergonômica de sensibilização e de assimilação, do porque deve ser feito deste jeito e não daquele, na medida em que ambicionamos que o $16^{\circ}$ Ergodesign - Congresso Internacional de Ergonomia e Usabilidade de Interfaces Humano Tecnológica: Produto, Informações Ambientes Construídos e Transporte

$16^{\circ}$ USIHC - Congresso Internacional de Ergonomia e Usabilidade de Interfaces Humano Computador

CINAHPA | 2017 - Congresso Internacional de Ambientes Hipermídia para Aprendizagem.
Neste contexto é valido complementar que as reflexões ergonômicas para o autor são premissas fundamentais na pratica projetual, e deverá ser consolidada por análises, diagnósticos e comentários sobre o s problemas típicos ergonômicos mais comumente detectados nos objetos que se observam, se constatam ou se detectam e que se referem como ás características de configuração física e ás qualidades de uso funcionais e perceptíveis bem como as interfaces recíprocas.

O Sistema Técnico de Leitura proposto pelo autor Gomes Filho (2003) se fundamenta como um todo nos seguintes itens: 1 . Fatores ergonômicos básicos; (divididos em seus respectivos blocos conceituais: a) Requisitos de projeto, b) Ações de manejo e c) Ações de Percepção); 2. Signos visuais e 3. Códigos visuais. Os Fatores Ergonômicos Básicos (FEB) neste artigo são apresentados de forma sucinta nos seguintes sub capítulos são fundamentados conforme quadro 01 :

Quadro 01: Fatores ergonômicos básicos

\begin{tabular}{|c|c|c|}
\hline \multicolumn{3}{|c|}{ FATORES ERGONÔMICOS BÁSICOS } \\
\hline $\begin{array}{l}\text { REQUISITOS DE } \\
\text { PROJETO }\end{array}$ & $\begin{array}{c}\text { AÇÕES DE } \\
\text { PERCEPCÃO }\end{array}$ & $\begin{array}{l}\text { AÇÕES DE } \\
\text { MANEJO }\end{array}$ \\
\hline 1. Tarefa & 1. Arranjo Espacial & $\begin{array}{l}\text { 1. Manuseio } \\
\text { Operacional }\end{array}$ \\
\hline 2. Segurança & & $\begin{array}{l}\text { 2. Atributos de } \\
\text { manejo e controle }\end{array}$ \\
\hline $\begin{array}{l}\text { 3. Conforto | } \\
\text { Desconforto }\end{array}$ & & $\begin{array}{l}\text { 3. Elementos Físicos } \\
\text { de manejo }\end{array}$ \\
\hline $\begin{array}{l}\text { 4. Estereótipo } \\
\text { popular }\end{array}$ & & $\begin{array}{l}\text { 4. Ações de } \\
\text { manuseio }\end{array}$ \\
\hline $\begin{array}{l}\text { 5. Envoltório e } \\
\text { Alcances Físicos }\end{array}$ & & \\
\hline 6. Postura & & \\
\hline $\begin{array}{l}\text { 7. Aplicações de } \\
\text { Força | Esforço }\end{array}$ & & \\
\hline 8. Materiais & & \\
\hline $\begin{array}{l}\text { 9. Usuário - } \\
\text { Habilidade | } \\
\text { Sensibilidade | } \\
\text { Precisão | } \\
\text { Treinamento } \\
\text { Especial }\end{array}$ & & \\
\hline $\begin{array}{l}\text { 10. Limpeza e } \\
\text { Manutenção }\end{array}$ & & \\
\hline
\end{tabular}

Fonte: Gomes Filho (2003, p. 24) adaptado pelo autor
Realização:

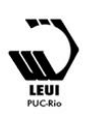




\section{$16^{\circ}$ \\ ERGODESIGN USIHC CINAHPA}

$16^{\circ}$ Ergodesign - Congresso Internacional de Ergonomia e Usabilidade de Interfaces Humano Tecnológica: Produto, Informações Ambientes Construídos e Transporte

$16^{\circ}$ USIHC - Congresso Internacional de Ergonomia e Usabilidade de Interfaces Humano Computador

CINAHPA | 2017 - Congresso Internacional de Ambientes Hipermídia para Aprendizagem.
De maneira geral, os requisitos de projeto são as diversas qualidades, a priori, para a materialização de um produto final, estes requisitos abrangem sua concepção nas fases de desenvolvimento do projeto e alcança até a sua fabricação ou confecção; as Ações de Percepção a constituem os elementos da informação que emitem estímulos que podem ou não ter significado para o receptor da informação, tudo dependerá dos fatores de percepção do ser humano, provocados por estímulos nos órgão sensoriais como visão, audição, tato e sinestésico; e as Ações de Manejo são observadas na manipulação de produtos e define-se o fator manuseio operacional como o ato de pegar, movimentar ou então pôr em funcionamento ou fazer cessar o funcionamento de um objeto.

\subsection{Posto de Trabalho Motorista de ônibus}

Para Grandjean (1998), a profissão dos motoristas de ônibus exige uma atenção prolongada e alerta que após 4 horas de trabalho chega-se às primeiras limitações da capacidade de produção, e que após 7 a 8 horas estas mesmas limitações aumentam fortemente. $\mathrm{O}$ autor coloca ainda que essas limitações sejam indicadores de um estado de fadiga. Os ergonomistas têm se preocupado com o motorista, principalmente com o seu espaço de trabalho, o que envolve a sua segurança e a sua capacidade de atender às exigências das empresas e dos passageiros (BERALDO, 2001). Toma-se como referencia o entendimento da importância do design ao estudo de postos de trabalho do autor Iida (2005) que entende que o design dos postos de trabalho busca acomodar o usuário com conforto, contentamento e liberdade para execução de tarefas com o máximo de produtividade.

Analisando a tarefa do motorista de ônibus, Saporta (2000), cita a existência de quatro critérios que definem um assento | poltrona confortável para o motorista:

- $\mathrm{O}$ assento deve proporcionar ao motorista total visibilidade e alcance dos controles e instrumentos;

- $\mathrm{O}$ assento tem que acomodar todos os tipos e tamanhos de motoristas independente do modelo;

- O assento deve ser confortável por longos períodos permitindo a alternância de postura, com tecidos que não absorvam o calor e com existência de ajustes lombares; - $\mathrm{O}$ assento deve ser uma zona de segurança para o motorista

\subsubsection{Riscos da Posição Sentado: motorista de onibus}

Constatam Peacock e Karwowski (1993), que o assento ou poltrona, é uma importante interface entre o motorista e o veículo. Os ajustes eficientes da poltrona conforme o tipo e preferência do motorista são importantes não só para o seu conforto, mas para suportar a postura exigida durante a execução das atividades ao dirigir e que, portanto o conforto, a saúde e a segurança do motorista são os três critérios fundamentais para a concepção dos assentos. Porém segundo Parsons (2000), é comum encontrar estudos que avaliem os assentos dos motoristas de ônibus como "pobres" quanto à concepção e que geram desconforto, resultando em dores musculares e problemas lombares.

A posição sentada por um tempo longo, como no trajeto de motoristas de ônibus rodoviário interestaduais, pode causar desconforto em diferentes aspectos: desde fadiga muscular, pressão sanguínea, desestabilidade, problemas na coluna, principalmente na região lombar. Panero e Zelnik (2002) apontam que um dos maiores problemas é que o sentar-se é freqüentemente visto como uma atividade estática, quando na verdade é uma ação dinâmica. Outros postulados teóricos auxiliam na construção da problemática da pesquisa, tal como o de Carson (1993), que afirma que na postura sentada, ocorre um aumento nas pressões na coluna vertebral, coxas, nádegas, que poderão, ao mesmo tempo, favorecer o surgimento de posturas inadequadas, podendo aumentar, caso o sujeito permanecer sentado por um tempo mais prolongado. Ficar sentado por um período longo acarreta fadiga, principalmente na região do pescoço e cabeça, o que poderia ser amenizado com pausas regulares durante o trabalho ou trajeto de ônibus (CORLETT e MANENICA, 1980). $O$ autores LEMOS \& VINGLA \& MORETTO (2011) em seu artigo: Análise de desconforto na
Realização:

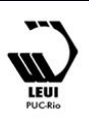




\section{$16^{\circ}$ \\ ERGODESIGN USIHC CINAHPA}

posição sentada em viagens de ônibus, apontam como aspecto de pesquisa o conforto no desenvolvimento de projetos de assentos de ônibus, na leitura dos resultados e discussão o artigo apresenta aspectos relevantes na opinião de usuários de ônibus rodoviário, a abordagem da pesquisa quantitativa aponta sobre o índice de desconforto dos passageiros está primeiramente na região lombo-sacro depois pescoço e então finalmente no pescoço. A pesquisa também apontou sobre o que mais causa desconforto na poltrona e por ordem de relevância, seguiram as seguintes: espaço para pernas, altura do encosto, encosto inclinado, apoio para pescoço e apoio para lombar. A conclusão do estudo dos autores indicou uma insatisfação e um desconforto dos passageiros de ônibus entrevistados com relação á poltrona que utilizaram durante a viagem, sendo que a imobilidade na postura sentada e as limitações no espaço da poltrona e as consequentes posições assumidas levam ao usuário a uma acomodação na busca do conforto.

\section{Resultados}

A pesquisa foi submetida e aprovada ao Conselho de Ética (CEP), com o número CAAE

19578913.9.0000.0118. Para as etapas da pesquisa experimental, cada sujeito era submetido ao Termo de Consentimento Livre e Esclarecido (TCLE), consentimento para fotografias, vídeos e gravações, baseado nos princípios do Conselho Nacional de Saúde, por meio da Resolução ${ }^{\circ}$ 466/2012 - CNS.

Analisando o processo de pesquisa de campo, os resultados obtidos permeiam pelas seguintes etapas:

$\mathrm{Na}$ Etapa 1 com a aplicação de entrevistas estruturadas diretas com designers de produto de empresa carroceira e pesquisa de campo sobre o processo de desenvolvimento de produto na empresa. Foram contatados 7 profissionais de uma empresa carroceira, entre estes estão 4 designers e 3 engenheiros de desenvolvimento de produto. Desta amostra pesquisada, notou-se uma postura similar e padronizada com relação às perguntas da pesquisa. Todos os sujeitos participam efetivamente do Comitê de Produto Integrado da empresa (reunião entre os profissionais envolvidos $16^{\circ}$ Ergodesign - Congresso Internacional de Ergonomia e Usabilidade de Interfaces Humano Tecnológica: Produto, Informações Ambientes Construídos e Transporte

$16^{\circ}$ USIHC - Congresso Internacional de Ergonomia e Usabilidade de Interfaces Humano Computador

CINAHPA | 2017 - Congresso Internacional de Ambientes Hipermídia para Aprendizagem.

no processo de desenvolvimento de produto) e que têm visão holística de todos os processos, componentes e fases desde planejamento, desenvolvimento e produção. De maneira geral a entrevista foi fundamental para a pesquisa mediando aspectos sobre os conceitos de desenvolvimento de produto da empresa, bem como, sobre as especificidades dos assentos do motorista. De fato a empresa não fabrica este artefato e ou componente, mas verificou-se que há prioridades específicas para se estabelecer junto ao fornecedor, como respeitar as medidas normativas, independentemente da região, testes de segurança com cinto de segurança e cálculo de estrutura e conforto para proporcionar ao motorista um trabalho com pouca fadiga muscular. Neste sentido também foi abordado durante a entrevista perguntas relacionadas aos fatores ergonômicos para concepção projetual e neste aspecto os profissionais demonstraram existir apenas pesquisas de satisfação do cliente, mas não são delineadas por métricas ergonômicas, de fato apontaram que deveriam existir ferramentas de análises mais eficazes e de rápida aplicação para serem utilizadas no início da fase projetual e também nas fases de testes e adequações. Na Etapa 02 da pesquisa destinou-se à observação do processo de desenvolvimento e fabricação de ônibus rodoviário da empresa carroceira, no setor de produção, com acompanhamento de dois técnicos, dois engenheiros e um projetista da empresa. Conforme a visitas dos setores da empresa, os profissionais que acompanharam a visita técnica detalharam os processos e demonstraram os requisitos analisados em modelo de um dos produtos da empresa que são propostos pelas fichas desenvolvimento presentes na empresa. A empresa pesquisada é uma sociedade anônima de capital aberto, com mais de 25 anos de atuação, e tem por principal objetivo a fabricação de carrocerias para ônibus e componentes, além de produzir ônibus, é oferecer soluções de transporte inteligentes. A sua linha de produtos abrange uma ampla variedade de modelos, composta pelos grupos de rodoviários, urbanos, micro, e minis. Possui duas unidades fabris com processo verticalizado de produção e é uma das principais fabricantes de carrocerias de ônibus do país. A produção atinge 20 ônibus/dia. São mais de 2.800
Realização:

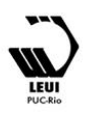




\section{$16^{\circ}$ \\ ERGODESIGN USIHC CINAHPA}

colaboradores em parques fabris de 145 mil metros quadrados. O desenvolvimento do produto da empresa é centrado no usuário, desta forma verificou-se que o desempenho avaliado em termos de benefícios humanos e satisfação do cliente são muito positivos, pois uma abordagem centrada no usuário tem como base projetual em esforço interdisciplinar avaliando a análise das tarefas humanas, suas capacidades e necessidades no âmbito do contexto de seu uso. Pôde-se descrever o processo de desenvolvimento de produto em três macro fases: pré-desenvolvimento, desenvolvimento e pós desenvolvimento. Um dos aspectos mais importantes desta etapa converge na seguinte constatação: no setor de montagem das poltronas e assentos, existem duas linhas paralelas de montagem: uma para poltronas de ônibus urbanos e outra para poltronas de ônibus rodoviários. Ao longo de cada linha, existem os seguintes postos de trabalho: pré-montagem da estrutura metálica da poltrona, quando sua base é parafusada ao encosto; ensacamento, quando é colocada a capa da poltrona; fechamento do ensacamento e colocação do assento. As atividades realizadas em cada posto possuem pequenas variações em função do modelo de poltrona. Nesta etapa de pesquisa de campo pôde dimensionar o sistema produtivo da empresa, de forma a fazer o pesquisador relatar algumas deficiências e algumas lacunas sobre a cabine do motorista e seu assento. De fato a empresa realiza pesquisas sobre este componente estruturante do interior do veículo, porém, não são aplicadas na fase inicial do produto, permanecem se adaptando conforme o processo fabril. Nas figura 1 e 2 são registrados em destaque os setores de desenvolvimento do habitáculo do motorista, sendo este um dos locais mais importantes para visitação nesta pesquisa, onde se podem verificar os ajustes e regulagens que devem ser feitos no posicionamento do mesmo com relação a todos os componentes da cabine.

Figura 1: Montagem estrutural do habitáculo do motorista e posicionamento do assento $16^{\circ}$ Ergodesign - Congresso Internacional de Ergonomia e Usabilidade de Interfaces Humano Tecnológica: Produto, Informações Ambientes Construídos e Transporte

$16^{\circ}$ USIHC - Congresso Internacional de Ergonomia e Usabilidade de Interfaces Humano Computador

CINAHPA | 2017 - Congresso Internacional de Ambientes Hipermídia para Aprendizagem.

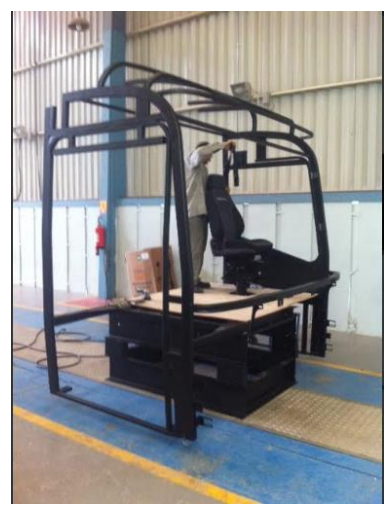

Fonte: dados de pesquisa de campo.

Figura 2: Montagem estrutural do habitáculo do motorista e posicionamento do assento

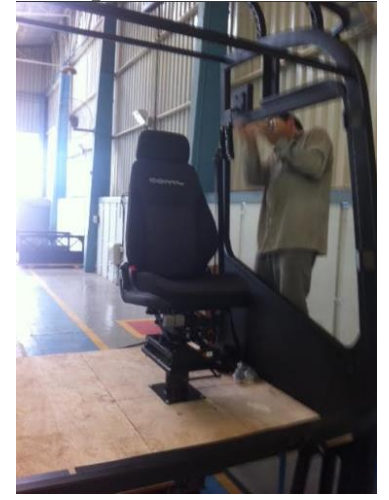

Fonte: dados de pesquisa de campo.

Percebeu-se que no setor de montagem das poltronas e assentos, existem duas linhas paralelas de montagem: uma para poltronas de ônibus urbanos e outra para poltronas de ônibus rodoviários. Ao longo de cada linha, existem os seguintes postos de trabalho: pré-montagem da estrutura metálica da poltrona, quando sua base é parafusada ao encosto; ensacamento, quando é colocada a capa da poltrona; fechamento do ensacamento e colocação do assento. As atividades realizadas em cada posto possuem pequenas variações em função do modelo de poltrona. Na Etapa 3 a Avaliação antropométrica foi realizada por meio de análises de medidas definidas pelo protocolo Norma DIN (33402) e métricas brasileiras. Nesta etapa foram realizadas medições antropométricas com 08 oito motoristas de ônibus rodoviário de uma empresa de Chapecó (SC) do setor de turismo, que possui ônibus leito, por meio da medição do protocolo de postura sentada, após medidas foram comparadas com as 


\section{$16^{\circ}$ \\ ERGODESIGN USIHC CINAHPA}

normas DIN 33402 e métricas brasileiras existentes, para verificação da média entre elas. Jin et al. (2001) dizem que dez dados antropométricos são fundamentais para o projeto de cabina de um veículo, sendo eles: altura dos olhos, altura dos ombros, altura dos cotovelos, profundidade do corpo, diâmetro da coxa, comprimento do braço e antebraço, largura de ombro a ombro, diâmetro da pega e dimensões das tuberosidades isquiáticas. Peacock e Karwowski (1993) apresentaram dois parâmetros antropométricos que precisam ser considerados no projeto para o posto do motorista, que são as mensurações estáticas e as mensurações funcionais. As mensurações estáticas consideram as dimensões do corpo em posição estática. Esta mensuração inclui as seguintes medidas: altura do usuário em pé; altura do usuário sentado; altura dos olhos na posição sentada; altura superior da perna; altura do joelho; comprimento do assento; altura superior e inferior do braço; alcance total do braço; largura dos ombros; peso do usuário. Como resulta desta etapa constatou-se que há pequenas variações de medidas, portanto as medidas aqui identificadas com relação às medidas antropométricas utilizadas na concepção de espaços interiores de ônibus são similares e não possuem diferenças consideráveis, pois segundo Peacock e Karwowski (1993), em média, os motorista de ônibus desenvolvem suas manobras num espaço de: $105 \mathrm{~cm}$, da cadeira ao painel; $72 \mathrm{~cm}$, da cadeira ao volante da direção; 82 $\mathrm{cm}$, da janela à esquerda ao câmbio de marcha (à direita do motorista); $89 \mathrm{~cm}$, da janela à esquerda à caixa do motor (à direita do motorista); $156 \mathrm{~cm}$, da posição sentada ao teto. Analisando sob esta perspectiva, as medidas obtidas adaptam-se ao espaço de trabalho.

Na Etapa 4 a aplicação de questionário à motoristas de ônibus rodoviário, a fim de avaliar os fatores ergonômicos básicos gerados durante o uso do assento. Foram elaboradas 52: perguntas de múltipla escolha e 1 com ordem de preferência com mais alternativas de escolha. Durante o processo de aplicação do questionário percebeu-se poucas dúvidas sobre as perguntas e nenhum questionamento sobre as mesmas. As perguntas do questionário foram elaboradas conforme delineamento do sistema de leitura Ergonômica proposta por João Gomes Filho (2003), (detalhado $16^{\circ}$ Ergodesign - Congresso Internacional de Ergonomia e Usabilidade de Interfaces Humano Tecnológica: Produto, Informações Ambientes Construídos e Transporte

$16^{\circ}$ USIHC - Congresso Internacional de Ergonomia e Usabilidade de Interfaces Humano Computador

CINAHPA | 2017 - Congresso Internacional de Ambientes Hipermídia para Aprendizagem. na tabela 01 anteriormente apresentada) seguintes requisitos de projeto: tarefa, segurança, conforto $\backslash$ desconforto, estereótipo popular, Envoltórios e Alcances físicos Postura Aplicação de força esforço Materiais Usuário - habilidade, sensibilidade, precisão, treinamento, experiência Atributos de manejo de controle Elementos físicos de manejo Limpeza e manutenção, Arranjo espacial e Ações de percepção.

Também nesta etapa do estudo foram realizados registros fotográficos dos sujeitos identificando algumas premissas importantes, por exemplo: O motorista 3 vide figura 3 sente-se confortável com seu assento, não apontou nenhum desconforto. Porém demonstrou que seu assento possui ajustes por peso conforme figura 4 o sistema de molas regula os movimentos e ajustes da altura do assento conforme figura 6 . Bem como, apontou sobre os ajustes manuais que podem ser efetivamente realizados no volante de acordo com a necessidade de altura conforme ilustrado na Figura 5.

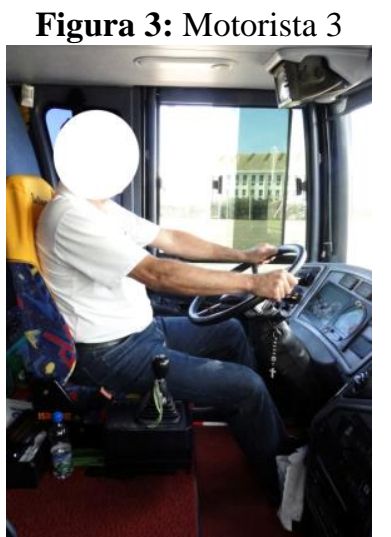

Fonte: dados de pesquisa de campo.

Figura 4: Assento Motorista 3 regulagem do peso e sistema de molas

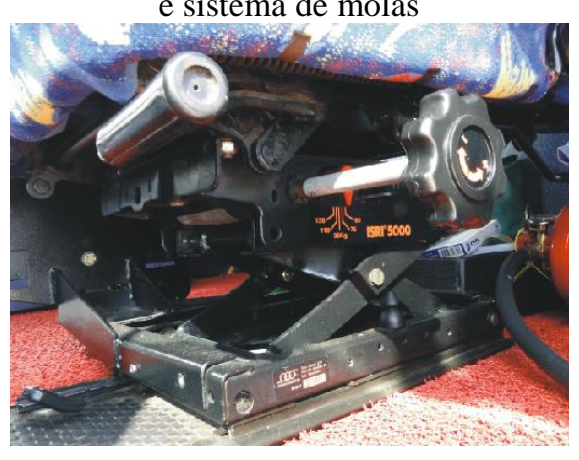

Fonte: dados de pesquisa de campo.
Realização:
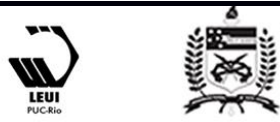


\section{$16^{\circ}$ \\ ERGODESIGN USIHC CINAHPA}

$16^{\circ}$ Ergodesign - Congresso Internacional de Ergonomia e Usabilidade de Interfaces Humano Tecnológica: Produto, Informações Ambientes Construídos e Transporte

$16^{\circ}$ USIHC - Congresso Internacional de Ergonomia e Usabilidade de Interfaces Humano Computador

CINAHPA | 2017 - Congresso Internacional de Ambientes Hipermídia para Aprendizagem.
Figura 5: Volante Motorista 3 regulagem da altura

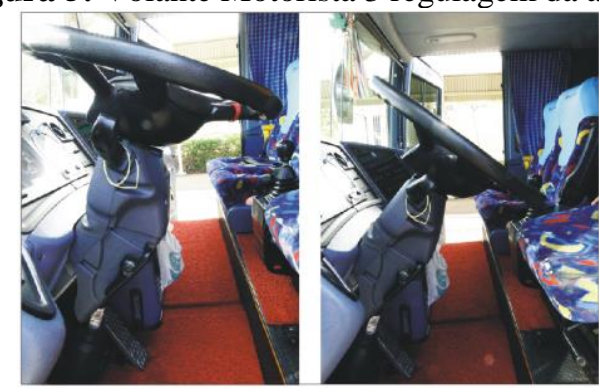

Fonte: dados de pesquisa de campo.

Sobre os ajustes das poltronas, concorda-se com Occhipint et al. (1993), que afirmam que os vários ajustes da cadeira devem ser feitos de forma fácil e prática pelo usuário. Eles afirmaram que se os controles forem de difícil manipulação, de difícil alcance, não corresponderem ao acionamento das alavancas, ou que requeiram muita força, eles não serão usados.

O motorista 5, sente-se confortável com seu assento, não apontou nenhum desconforto e demonstrou conforme figura 6 o sistema de amortecimento do assento por meio do sistema a ar, o que reflete na eficácia, segurança e eficiência do assento no quesito ajustes dos movimentos.

Figura 6: Assento do Motorista 5 - regulagem

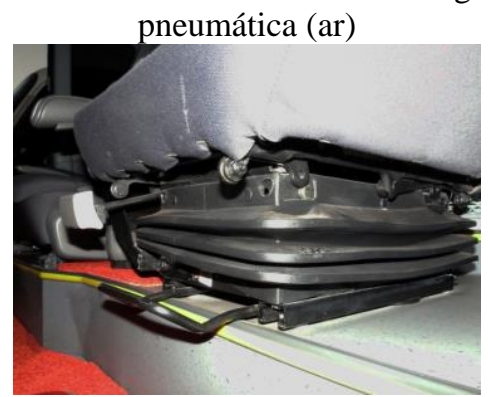

Fonte: dados de pesquisa de campo.

A poltrona do motorista 7, vide figura 7, sente-se desconfortável com relação ao material do assento mostrado na figura 8 . Este é recoberto com courino, que não favorece a transpiração e provoca irritações na pele quando a temperatura mais quente.

Figura 7: Assento do Motorista 7

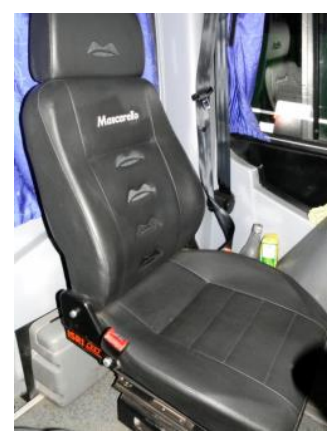

Fonte: dados de pesquisa de campo.

Neste aspecto, concorda-se com Pheasant (1986) que os materiais de revestimentos devem ser porosos para permitirem a ventilação e ásperos para proporcionarem estabilidade.

Todos os assentos avaliados, e registrados nesta pesquisa possuem regulagem de altura e distância, como também, possuem amortecedores que propiciam melhor conforto, diminuindo a absorção das vibrações provenientes do veículo em movimento. De maneira geral, os sujeitos com peso e estatura dentro de um padrão médio normal, não encontram dificuldades quanto ao conforto. Entretanto, que estejam fora deste padrão, podem encontrar dificuldades ergonômicas. Portanto, entende-se que as empresas devem atentar para a adequação do posto de trabalho, de acordo com as características particulares de cada profissional. Por fim, foi na Etapa 5 foi realizado um cruzamento de dados, das entrevistas com designers com relação aos dados dos questionários aplicados com os motoristas, com análise dos fatores ergonômicos, sob a óptica dos FEB propostos por Gomes Filho (2003).

Para compreender melhor foi realizado um demonstrativo da análise da tarefa de dirigir, conforme quadro 1 , baseado no sistema técnico de leitura apresentado no item 2.1, a descrição das Ações: dirigir ônibus rodoviário longa distância com base referencial proposto por IIDA (2005, p.199):

\footnotetext{
"As ações devem ser descritas em um nível mais detalhado que a análise de tarefa, elas se centram nas características que influem no projeto de interface homem-máquina e se classificam em informações e controles. As informações referem-se ás interações em nível
}

Realização:

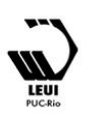


$16^{\circ}$ Ergodesign - Congresso Internacional de Ergonomia e Usabilidade de Interfaces Humano Tecnológica: Produto, Informações Ambientes Construídos e Transporte

$16^{\circ}$ USIHC - Congresso Internacional de Ergonomia e Usabilidade de Interfaces Humano Computador

CINAHPA | 2017 - Congresso Internacional de Ambientes Hipermídia para Aprendizagem. sensorial do homem, os controles, em nível motor ou das atividades musculares."

Quadro 2:.Análise de tarefa: dirigir ônibus

\begin{tabular}{|c|c|c|}
\hline \multicolumn{3}{|c|}{ DIRIGIR ONIBUS RODOVIÁRIO - tarefa altamente repetitiva } \\
\hline AÇ̃̃O & CONTROLE & INFORMAÇÕES \\
\hline $\begin{array}{l}\text { Manejo de controles } \\
\text { de frenagem }\end{array}$ & $\begin{array}{c}\text { Membros superiores } \\
\text { e inferiores - } \\
\text { atenção }\end{array}$ & Físicos e cognitivos \\
\hline $\begin{array}{c}\text { Segurar e manejar o } \\
\text { volante - curvas ou } \\
\text { não }\end{array}$ & $\begin{array}{c}\text { Membros superiores } \\
\text { e inferiores }\end{array}$ & Físicos e cognitivos \\
\hline $\begin{array}{l}\text { Manter a atenção } \\
\text { (visão) e ou } \\
\text { visibilidade }\end{array}$ & $\begin{array}{c}\text { Precisão de atenção } \\
\text { mental }\end{array}$ & Cognitivos \\
\hline $\begin{array}{l}\text { Ajustes de posição e } \\
\text { de altura do assento }\end{array}$ & $\begin{array}{c}\text { Membros superiores } \\
\text { e inferiores }\end{array}$ & Físicos \\
\hline $\begin{array}{c}\text { Alcances dos } \\
\text { dispositivos baixos }\end{array}$ & $\begin{array}{c}\text { Membros superiores } \\
\text { e inferiores }\end{array}$ & Físicos \\
\hline $\begin{array}{c}\text { Alcances dos } \\
\text { dispositivos altos }\end{array}$ & $\begin{array}{c}\text { Membros superiores } \\
\text { e inferiores }\end{array}$ & Físicos \\
\hline $\begin{array}{l}\text { Atendimento ao } \\
\text { passageiro }\end{array}$ & $\begin{array}{c}\text { Precisão de atenção } \\
\text { mental }\end{array}$ & Físicos e cognitivos \\
\hline Acender luz - som & $\begin{array}{c}\text { Membros superiores } \\
\text { e inferiores e } \\
\text { sensibilidade } \\
\text { sinestésica }\end{array}$ & Físicos e cognitivos \\
\hline
\end{tabular}

Fonte: A pesquisadora - Adaptado Iida (2005:199).

Em um segundo momento foi elaborado um cruzamento dos dados obtidos entre os questionários aplicados com motoristas e as entrevistas aplicadas com os profissionais da empresa, analisando os fatores ergonômicos básicos sob a óptica do sistema técnico de leitura ergonômico proposto por Gomes Filho (2003), conforme check- list com 15 itens dos FEB (Fatores Ergonômicos Básicos), apresentado a seguir. Porém antes de apresentar o check list é necessário abordar o contexto teórico proposto por Gomes Filho (2003: 25):

"O sistema de leitura ergonômica do objeto se consolida como um todo nos itens: 1. Fatores ergonômicos básicos (divididos em seus respectivos blocos conceituais: Requisitos de projeto, Ações de manejo e ações de percepção); 2. Signos Visuais e 3. Códigos Visuais. (...) Os requisito de projeto são diversas qualidades desejadas, a priori, para a materialização de um produto final. Abrange sua concepção e fases de desenvolvimento de projeto e, eventualmente, alcança até sua fabricação. Tudo isso, naturalmente, consoante com a categoria, a classe, o tipo e demais atributos e especificidades inerentes ao citado produto. [...]"

\section{1 - Requisito de projeto: Tarefa}

» Trajeto de 08 a 10 horas por viagem,

» Frequência de descanso é de três vezes a cada viagem,

»O Tempo de parada 30 minutos, » A principais ações são: 1) segurar e manejar o volante, (2) manejo de controle de frenagem e aceleração, (3) troca de marchas, (4) atenção de tráfego e estrada, (5) atenção do painel de controle e sinais de alerta, (6) atendimento ao passageiro.

\section{2- Requisito de projeto: Seguranca}

» Os sinais de alertas que são gerados à problemas técnicos ou mecânicos são visuais e sonoros.

» Os controles de direção e acionamentos e outras funções são de fácil entendimento.

»Quando acionado, os sistemas de Tração

(frenagem) há na maioria a percepção de segurança neste procedimento em relação ao veículo, quando não é devido a falhas na manutenção.

»O Cinto de segurança é sim utilizado com que frequência pela maioria. Os sistemas de travas e acionamento de segurança são de fácil manuseio e utilização.

» Sobre os acionamentos de ancoragem e cintos de segurança, são seguidas as normas CONTRAN (Conselho Nacional de Transporte), Associação Brasileira de Normas Técnicas ABNT: NBR 6060 e NBR 6606; e o Regulamento dos serviços rodoviários interestaduais e internacionais de transporte coletivo de passageiros. Ministério dos transportes, Departamento Nacional de Estradas e Rodagem.

» No interior do veículo, é primordial inspecionar visualmente os pontos de fixação do cinto de segurança quanto ao estado geral da estrutura (se necessário retirar o assento do banco traseiro), o estudo ergonômico é um processo de inspeção de técnicos que analisam o posicionamento dos pontos de ancoragem dos cintos de segurança no veículo, verificando se está em posição ergonômica adequada.

» No meio do curso do banco (ajuste longitudinal), a fixação dos cintos à estrutura do veículo deve se dar no prolongamento da bissetriz do ângulo formado pelas linhas médias do assento e encosto
Realização:

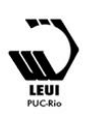




\section{$16^{\circ}$ \\ ERGODESIGN USIHC CINAHPA}

$16^{\circ}$ Ergodesign - Congresso Internacional de Ergonomia e Usabilidade de Interfaces Humano Tecnológica: Produto, Informações Ambientes Construídos e Transporte

$16^{\circ}$ USIHC - Congresso Internacional de Ergonomia e Usabilidade de Interfaces Humano Computador

CINAHPA | 2017 - Congresso Internacional de Ambientes Hipermídia para Aprendizagem. (para bancos com regulagem contínua de encosto, este deve formar um ângulo de $25^{\circ}$ com a vertical), deve se localizar acima da altura dos ombros, devendo o cinto passar na parte central da clavícula da pessoa sentada.

»O técnico ainda realiza medidas da distância entre a fixação inferior dos cintos, respeitando o mínimo de $350 \mathrm{~mm}$.

» Na parte inferior do veículo, inspecionar visualmente os pontos de fixação dos cintos de segurança, quanto ao estado geral e a existência de cobre junta metálica (para distribuição das tensões).

» Mede-se ainda o diâmetro dos parafusos de ancoragem dos cintos, é admitido um diâmetro mínimo de $12 \mathrm{~mm}$ (classe 8.8) para fixação simples e dupla. No caso de se usar um parafuso passante, este deve possuir arruela lisa, arruela de pressão e porca autotravante | frenante.

\section{3- Requisitos de projeto: Conforto}

» Quando acionado os sistemas de Tração (frenagem) os desconfortos físicos gerados são de exercer força para manter os braços no controle da direção.

» A região de maior desconforto que enfrenta ao dirigir por longo período de tempo: dores na coluna por mau posicionamento.

» Os movimentos são mais frequentes que despende de força física e causam desconforto, costuma fazer é durante a Direção do volante. » A postura mais desconfortável durante a direção é manter a coluna ereta e exercer força para manter os braços no controle da direção.

» Outro desconforto, além do postural, você relaciona ao uso do assento de ônibus é a dormência muscular.

» Região do tronco que mais sente desconforto:

Lombar.

» Sobre as dores nas articulações, a mais frequente: Membros inferiores (pernas, joelhos e tornozelos). » A altura do assento em relação ao piso do ônibus causa algum desconforto apenas na regulagem para mais baixo, pois tem um limite inferior que a regulagem para cima.

» A maioria a profundidade do assento não causa algum desconforto, porém foi relatado que: não há regulagem da base do assento.

»O descanso para braços é utilizado com muita frequência, porém é um acessório a ser adquirido pelo comprador e não existem em todos os veículos.

» Realiza o ajuste de regulagem do assento por sentir algum desconforto; de 5 á dez vezes no trajeto.

» A ação que exige maior desconforto e é mais desagradável é segurar e manejar o volante com o movimento de braços e antebraços.

04- Requisitos de projeto: Estereótipos Popular » A prevalência do uso da mão: são destros. »O perfil dos motoristas tiveram a preparação para direção defensiva.

\section{5- - Requisitos de projeto: Envoltórios e} Alcances físicos

»O assento proporciona alcance a todos os comandos.

» A visibilidade do painel está de acordo com as ações realizadas em relação à posição do assento. » $\mathrm{O}$ controle de tração e aceleração possui alguma dificuldade para serem acionados na maioria não, porém foi relatado que: Pela falta de manutenção às vezes apresenta falhas.

» No manejo das marchas encontra alguma dificuldade, na maioria não, porém foi relatado que: Pela falta de manutenção às vezes apresenta falhas.

\section{6- Requisitos de projeto: Postura}

» A postura mais freqüentemente repetida é segurar e manejar o volante,

» A postura mais longa mantida é segurar e manejar o volante e na troca de marchas (movimento de braços e antebraços) e manejo de controles de frenagem (movimento de pernas e pés),

» A postura a que exige mais força é o tencionamento do corpo inteiro para tração e curvas acentuadas.

\section{7- Requisitos de projeto: Aplicação de forca - esforco}

»O esforço que demanda maior aplicação de força, é o tencionamento do corpo inteiro para tração e curvas acentuadas.

\section{8 - Requisitos de projeto: Materiais}

Realização:

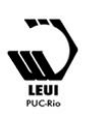




\section{$16^{\circ}$ \\ ERGODESIGN USIHC CINAHPA}

» $\mathrm{O}$ material aplicado no assento vão desde têxteis, polímeros á aço galvanizado para estrutura, » A escolha depende do modelo e dos requisitos que devem ser cumpridos pelas normas vigentes na ABNT e CONTRAN.

\section{9- Requisitos de projeto: Usuário - perfil}

» Idade 40 a 45 anos,

» Atura média 1,70 á 1,80m.

» Peso médio de 80 á $90 \mathrm{~kg}$.

» Biotipo físico; mesomorfo.

» Possui algum problema de saúde que o impede de realizar atividades vinculadas à direção: na maioria nenhum, porém houve indícios de dores coluna.

» Na maioria não pratica exercícios regulares.

» Hábitos alimentares não são acompanhados de controle nutricional.

» Sofreu algum tipo de lesão provocado pela ação de dirigir: houve poucos, porém Dores da coluna crônicas - dores nas articulações.

» Quando propostos pela empresa contratante realizam atividades práticas laborais durante ou após o trabalho.

» A frequência que procura médico para exames posturais apenas em caso de extrema necessidade.

10- Requisitos de projeto: Nível de qualificação - habilidade, treinamento, experiência

» Possuem Formação instrutiva de direção: renovação e periódicos exames médicos » aulas regulares de instrução defensivas. » Anos de profissão: 10 á 12 anos.

\section{1 - Requisitos de projeto: Atributos de manejo}

\section{de controle}

» As maiores dificuldades com o assento em relação ao manuseio dos comandos de direção está diretamente ligado ao movimento para realizar curvas, alcances dos dispositivos baixos e manter a atenção (visão) e ou visibilidade.

\section{2- Requisitos de projeto: Elementos físicos de manejo}

»Os elementos físicos de manejo do habitáculo são dispositivos na maioria em formato orgânicos arredondados apresentam textura em alguns.

» Estes dispositivos são de fácil leitura e compreensão $16^{\circ}$ Ergodesign - Congresso Internacional de Ergonomia e Usabilidade de Interfaces Humano Tecnológica: Produto, Informações Ambientes Construídos e Transporte

$16^{\circ}$ USIHC - Congresso Internacional de Ergonomia e Usabilidade de Interfaces Humano Computador

CINAHPA | 2017 - Congresso Internacional de Ambientes Hipermídia para Aprendizagem.
» Sobre a estrutura é composta por: Estrutura da carroceria, componentes de isolamento térmico e acústico, teto interno, porta pacotes, componentes de iluminação e sonorização, painel de controle e comandos de direção e assento motorista.

\section{3 - Requisitos de projeto: Limpeza e manutencão}

»A maior dificuldade encontrada na limpeza e manutenção do habitáculo e ou assento está nos apertos, ajustes e reparos na estrutura.

» Sobre o aspecto funcional, sempre se indica e se deve realizar assistência técnica em relação aos cuidados com conservação limpeza que constam nos serviços on line e atendimento ao consumidor.

\section{4 - Requisitos de projeto: Arranjo espacial}

»A distribuição dos componentes do habitáculo como peças, dispositivos de controle e de direção, os instrumentos de informação estão adequados de modo coerente á sua tarefa.

» Alguns veículos ainda, o volante não possui regulagem de altura para a distância e altura do assento.

» Os controles de som e vídeo ficam fora do alcance (alto ou na parte interna do veículo).

\section{5 - Requisitos de projeto: Aç̃es de percepcão}

» Os sinais de alertas que são gerados quando há problemas técnicos ou mecânicos são visuais e sonoros.

» O painel e símbolos encontrados para manuseálo assim como utilizar o assento são de fácil leitura e entendimento.

»Quanto aos aspectos de luminosidade de seu habitáculo quando há falta de manutenção elétrica é identificado: baixa luminosidade dos sinais do painel para noite.

» A trepidação e os ruídos provocados pelo do motor / estrada são constantes e pouco prejudicam a dirigibilidade nos aspectos de atenção e concentração.

» Durante o trabalho sentem desconforto relacionado á temperatura que interferem no seu conforto térmico. Neste caso os sujeitos indicaram assento de material têxtil mais indicado para o uso. » É preciso verificar se há interferência ou dificuldade na sua condução, tais como: dificuldade de acionamento dos pedais, folgas no 


\section{$16^{\circ}$ \\ ERGODESIGN USIHC CINAHPA}

volante e nos pedais, câmbio e pedais duros, aceleração, relação peso/potência, freio de estacionamento, cinto de segurança, equipamentos e acessórios.

\section{Considerações Finais}

O cruzamento de dados aqui desenvolvido, aponta os FEB dos assentos para motoristas de ônibus rodoviário, um sistema técnico de leitura ergonômica rápido de ser aplicado e diagnosticado, podendo auxiliar no apontamento de fatores condicionantes ao risco desenvolvimento de desconforto do motorista, ferramenta esta que pode se diagnosticar uma série de requisitos básicos para projetação deste artefato.

O problema levantando sobre a contribuição da aplicação do sistema técnico de leitura ergonômica como ferramenta para auxiliar a projetistas, foi identificado principalmente na aplicação da entrevista com profissionais da área, que identificaram a necessidade de se ter uma ferramenta prática auxiliando na análise ergonômica principalmente na fase inicial do produto. E como observação para estudos futuros são lançados questões que podem ser aprofundadas: estudo de materiais aplicados em projetos de assentos, estudo delineando a antropometria funcional do motorista de ônibus enfatizando, principalmente os movimentos como elemento de avaliação ergonômica nos assentos; e estudo sobre a amplitude dos movimentos do motorista de ônibus levando em considerações os aspectos físicos e cognitivos. Nesse sentido, entende-se que existe muito a ser estudado sobre propostas para a melhoria da qualidade de vida dos motoristas de ônibus. Esta é uma apenas contribuição para a projeção de produtos e pesquisas que ainda virão para agregar ainda mais este repertório de aspectos ergonômicos ligados ao trabalho do motorista de ônibus.

\section{Referências bibliográficas}

BERALDO. L.C.; SCHEVER, J.C. Rede News. Revista Assobens. Editora. Volvo do Brasil Veículos. Curitiba:. N. 91.2001.P..4

FILHO, João Gomes. Ergonomia do Objeto, sistema técnico de leitura ergonômica. Escrituras, SP, 2003. $16^{\circ}$ Ergodesign - Congresso Internacional de Ergonomia e Usabilidade de Interfaces Humano Tecnológica: Produto, Informações Ambientes Construídos e Transporte

$16^{\circ}$ USIHC - Congresso Internacional de Ergonomia e Usabilidade de Interfaces Humano Computador

CINAHPA | 2017 - Congresso Internacional de Ambientes Hipermídia para Aprendizagem.

GRANDJEAN, E. Manual de ergonomia. Adaptando o trabalho ao homem. 4. ed Porto Alegre: Artes Médicas, 1998.

PANAERO, JULIUS. Anatomy for interior designers. New York: Whitney Library of Design, 1984.

CARSON, Roberta. Ergonomically Design Chair Adjust to individual demands. Occupational Health and Safety Magazine, June, 1993. p.71-75.

CORLET, E. N.; MANENICA, I. The effects and measurement of working postures. Applied Ergonomics, Trondheim, v.11, n.1, p.7-16, March, 1980.

IIDA Itiro: "Ergonomia Projeto e Produção". 2a edição. Editora Edgar Blucher, 2005.

JIN, C.; TIAN, X.; TIAN, Y.; TIAN, Q. Experimental study on fist-ellipse for Chinese auto drivers. China: Shanghai Coach Manufacturing Corporation, 2001.

LEMOS Carine \& VINGLA, Marília Silveira \& MORETTO, Luciane Cristina. Análise do desconforto postural na posição sentada em viagens de ônibus intermunicipais. FIEP BILLETIN - Volume 81 Special Edition - Article II, 2011. Disponível: http:/www.fiepbulletin.net

NORMA DIN 33402. Body dimensions of people; terms and definitions, measuring procedures. Beuth Verlag, 2005.

OCCHIPINTI, D.; COLOMBINI, D.; MOLTENI, G.; GRIECO, A. Criteria for the Ergonomic Evaluation of Work Chairs. La Med. del Lavoro, v. 84, p. 274-285, 1993.

PARSONS, K.C. Environmental Ergonomics: a review of principles, methods and models. Bristol: Ed. Taylor \& Francis, 2000.

PEACOCK, B.; KARWOWSKI,W. Automotive Ergonomics. London: Taylor \& Francis Ltda, 1993.

PHEASANT, Stephan. Body space: anthropometry, ergonomic and design. London: Taylor \& Francis, 1998.

SAPORTA, H. Durable Ergonomic Seating for Urban Bus Operators. Disponível em: <http://www.atucanada.ca/content_Health_And_Safety/ pdf/ergobus.pdf > Acesso em: 16 out 2012.
Realização:

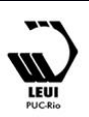

UNIVERSIDADE FEDERAL DE SANTA CATARINA 